\title{
Insulin sensitivity in calves decreases substantially during the first 3 months of life and is unaffected by weaning or fructo-oligosaccharide supplementation
}

\author{
A. J. Pantophlet, ${ }^{* 1}$ M. S. Gilbert, † J. J. G. C. van den Borne,† W. J. J. Gerrits, † M. G. Priebe, ${ }^{*}$ and R. J. Vonkł \\ *Department of Pediatrics; Center for Liver, Digestive and Metabolic Diseases, University Medical Centre Groningen, PO Box 30001 , \\ 9700 RB Groningen, the Netherlands \\ †Animal Nutrition Group, Wageningen University, PO Box 338, $6700 \mathrm{AH}$, Wageningen, the Netherlands \\ ¥Medical Biomics, University Medical Centre Groningen, PO Box 30001, 9700 RB, Groningen, the Netherlands
}

\begin{abstract}
Veal calves at the age of 4 to 6 mo often experience problems with glucose homeostasis, as indicated by postprandial hyperglycemia, hyperinsulinemia, and insulin resistance. It is not clear to what extent the ontogenetic development of calves or the feeding strategy [e.g., prolonged milk replacer (MR) feeding] contribute to this pathology. The objective of this study was therefore to analyze effects of MR feeding, weaning, and supplementation of short-chain fructo-oligosaccharides (FOS) on the development of glucose homeostasis and insulin sensitivity in calves during the first $3 \mathrm{mo}$ of life. Thirty male Holstein-Friesian calves $(18 \pm 0.7 \mathrm{~d}$ of age) were assigned to 1 of 3 dietary treatments: the control (CON) group received MR only, the FOS group received MR with the addition of short-chain FOS, and the solid feed $(\mathrm{SF})$ group was progressively weaned to $\mathrm{SF}$. The CON and FOS calves received an amount of MR, which gradually increased (from 400 to 1,400 g/d) during the 71-d trial period. For the SF calves, the amount of MR increased from 400 to $850 \mathrm{~g} / \mathrm{d}$ at d 30, and then gradually decreased, until completely weaned to only SF at d 63. The change in whole body insulin sensitivity was assessed by intravenous glucose tolerance tests. Milk tolerance tests were performed twice to assess changes in postprandial blood glucose, insulin, and nonesterified fatty acid responses. Whole-body insulin sensitivity was high at the start $(16.7 \pm 1.6 \times$ $\left.10^{-4}[\mu \mathrm{U} / \mathrm{mL}]^{-1}\right)$, but decreased with age to $4.2 \pm 0.6$ $\times 10^{-4}[\mu \mathrm{U} / \mathrm{mL}]^{-1}$ at the end of the trial. The decrease in insulin sensitivity was most pronounced ( $70 \%)$ between $\mathrm{d} 8$ and 29 of the trial. Dietary treatments
\end{abstract}

Received February 24, 2016.

Accepted May 7, 2016.

${ }^{1}$ Corresponding author: a.j.pantophlet@umcg.nl did not affect the decrease in insulin sensitivity. For CON and FOS calves, the postprandial insulin response was 3 -fold higher at the end of the trial than at the start, whereas the glucose response remained similar. The SF calves, however, showed pronounced hyperglycemia and hyperinsulinemia at the end of the trial, although weaning did not affect insulin sensitivity. We conclude that whole body insulin sensitivity decreases by $75 \%$ in calves during the first 3 mo of life. Weaning or supplementation of short-chain FOS does not affect this age-related decline in insulin sensitivity. Glucose homeostasis is not affected by supplementation of short-chain FOS in young calves, whereas postprandial responses of glucose and insulin to a MR meal strongly increase after weaning.

Key words: veal calf, weaned calf, insulin sensitivity, glucose homeostasis, fructo-oligosaccharide

\section{INTRODUCTION}

Veal calves are fed milk replacer (MR) and solid feed (SF; consisting of concentrates and roughages). The vast majority of ingested MR is directed into the abomasum through closure of the esophageal groove upon MR ingestion. Despite the tendency to increase the amounts of roughage and concentrates in veal calf diets, approximately 60 to $70 \%$ of the digestible nutrient intake originates from MR.

Milk replacer contains high amounts of lactose $(\sim 45 \%)$ and fat $(\sim 20 \%)$ on a DM basis. It has been shown that a prolonged intake of high levels of MR (hence large amounts of lactose and fat) may induce problems with glucose homeostasis and insulin sensitivity in heavy veal calves ( $>4$ mo old), as characterized by high incidences of hyperglycemia and hyperinsulinemia (Hostettler-Allen et al., 1994; Hugi et al., 1997). These problems may ultimately result in (pro)inflammatory stress and metabolic diseases, as evident from human studies (Hotamisligil, 2006; Shoelson et al., 2006), and 
hepatic steatosis (Gerrits et al., 2008). A previous study showed that replacing $33 \%$ of the lactose in the MR by fructose or glycerol improved postprandial glucose homeostasis (i.e., lower glucose and insulin peaks), but not insulin sensitivity in calves (Pantophlet et al., 2016). More interestingly, that study also showed that calves at $\sim 14$ wk of age are already relatively insensitive to insulin, compared with healthy nonruminants (Caumo et al., 2000; Stefanovski et al., 2011). Another study revealed that insulin sensitivity in neonatal dairy calves ( $<6$ wk of age) decreases from wk 3 to 6 , when calves are gradually weaned (Stanley et al., 2002). Moreover, Bach et al. (2013) reported that a greater level of MR allowance ( 8 vs. $4 \mathrm{~L} / \mathrm{d}$ ) had a negative effect on the development of insulin sensitivity in young calves (1-8 wk of age) with ad libitum access to starter feed. Yet, it remains unclear whether the decrease in insulin sensitivity in young calves can be influenced by feeding strategy (prolonged MR feeding vs. progressive weaning), or is explained by the ontogenetic development of calves. In contrast to dairy calves, veal calves are commonly maintained at diets containing large amounts of MR. Preventing the decrease in insulin sensitivity in veal calves during early life may augment the efficiency of energy utilization for growth and possibly also metabolic health in later life. This requires more insight in the changes in insulin sensitivity in young calves and underlying mechanisms (age- or diet-related).

In addition, the reduction in insulin sensitivity in young calves may - to some extent-be prevented by supplementation of short-chain fructo-oligosaccharides (FOS). Studies in various animal species have shown that dietary short-chain FOS affect whole body insulin sensitivity. In dogs and horses with obesity, for example, an increase in insulin sensitivity was measured after feeding FOS for a period of 6 wk (Respondek et al., 2008, 2011). The mechanisms behind the effects of short-chain FOS are poorly understood, but it has been hypothesized that short-chain FOS alters the intestinal microbiota composition, which directly or indirectly increases insulin sensitivity. In veal calves, oral short-chain FOS supplementation to a high-lactose MR decreased postprandial levels of plasma glucose and lactate, whereas insulin levels increased (Kaufhold et al., 2000). Whether this is due to changes in insulin sensitivity is not known, but if similar mechanisms operate in young calves then short-chain FOS supplementation may improve insulin sensitivity.

Therefore, the objective of this study was to assess age-related and diet-induced (i.e., MR only vs. $\mathrm{MR}+\mathrm{FOS}$ vs. progressive weaning) changes in wholebody glucose homeostasis and insulin sensitivity in veal calves during the first 3 mo of life.

\section{MATERIALS AND METHODS}

\section{Animals and Housing}

Thirty male Holstein-Friesian calves were housed at experimental facility "De Haar" of VanDrie Group, the Netherlands. At start of the trial, calves were $18 \pm 0.7$ $\mathrm{d}$ of age and weighed $44 \pm 0.3 \mathrm{~kg}$ (both mean $\pm \mathrm{SEM}$ ).

During the whole trial calves were housed individually, in $1.50 \times 1.10 \mathrm{~m}$ pens fitted with a wooden slatted floor and galvanized fencings. Ventilation occurred by ceiling fans, and illumination by natural light and artificial (fluorescent lamps) light between 0600 and 1800 h. The average temperature and humidity were 18.2 $\pm 0.1^{\circ} \mathrm{C}$ and $75.3 \pm 0.1 \%$, respectively (both mean \pm SEM).

Experimental procedures complied with the Dutch Law on Experimental Animals, and the ETS123 (Council of Europe 1985 and the 86/609/EEC Directive) and were approved by the Animal Care and Use Committee of Wageningen University.

\section{Experimental Design, Diets, and Feeding}

Calves were randomly assigned to 1 of 3 treatment groups: the control group (CON, $\mathrm{n}=10)$, fructo-oligosaccharide group (FOS, $\mathrm{n}=10$ ), or solid feed group $(\mathbf{S F}, \mathrm{n}=10)$.

Calves were fed amounts of MR (see Table 1 for MR composition) according to practical feeding schemes (Table 2), which were based on the expected BW. Body weight was measured weekly to monitor for any major deviations from the expected BW gain. The CON and FOS calves received similar amounts of MR, which increased from $400 \mathrm{~g} / \mathrm{d}$ at the start to $1,400 \mathrm{~g} / \mathrm{d}$ at the end of the trial. In addition, FOS calves received shortchain FOS supplementation (Profeed P95, Beghin-Meiji, Marckolsheim, France), which increased gradually from $0.8 \mathrm{~g} / \mathrm{d}$ on d 5 to $2.2 \mathrm{~g} / \mathrm{d}$ at the end of trial (d 71 ), and was equally divided over the 2 daily feedings and provided with the MR. For SF calves, the amount of MR increased from $400 \mathrm{~g} / \mathrm{d}$ at the start of trial to $850 \mathrm{~g} / \mathrm{d}$ at d 39 of the trial. Subsequently, the amount of MR gradually decreased to $250 \mathrm{~g} / \mathrm{d}$ at d 60 . From d 63 these calves were completely weaned to only SF.

In addition to MR, all calves received SF, which consisted of $70.9 \%$ concentrate, $14.5 \%$ wheat straw, and $14.6 \%$ alfalfa (based on DM). For CON and FOS calves, the amount of SF increased from 0 to $376 \mathrm{~g} / \mathrm{d}$ during the trial (Table 2), whereas this amount increased from 0 to $2,158 \mathrm{~g} / \mathrm{d}$ for $\mathrm{SF}$ calves.

Milk was fed at a concentration of $125 \mathrm{~g}$ of $\mathrm{MR} / \mathrm{L}$ reconstituted $\mathrm{MR}$ and supplied at a temperature of 
Table 1. Ingredient and nutrient composition of the milk replacer

\begin{tabular}{lc}
\hline Item & Value \\
\hline Ingredient (g/kg) & \\
Delactosed whey powder & 149.7 \\
Whey & 466.1 \\
Whey protein concentrate & 111.3 \\
Soy protein concentrate & 10.0 \\
Soluble wheat protein & 64.1 \\
Coconut oil & 49.2 \\
Lard & 52.5 \\
Tallow & 52.5 \\
Lecithin & 5.0 \\
Emulsifier & 5.0 \\
Premix & 10 \\
Calcium formate & 8.4 \\
Methionine & 2.1 \\
Lysine & 10.0 \\
Threonine & 2.0 \\
Calcium carbonate & 2.5 \\
Nutrient & \\
DM (g/kg) & \\
CP (N $\times 6.25)$ & 978 \\
Crude fat & 207 \\
Crude ash & 193 \\
Lactose & 86 \\
Fe (mg/kg of DM) & 473 \\
\hline Prix (per & 45.9 \\
\hline
\end{tabular}

${ }^{1}$ Premix (per kg of milk replacer): $\mathrm{CP}, 0.7 \mathrm{~g}$; starch, $5.0 \mathrm{~g}$; crude ash $1.5 \mathrm{~g}$; Ca, $16.6 \mathrm{mg}$; P, $7.5 \mathrm{mg}$; Na, $0.7 \mathrm{mg}$ K, $7.3 \mathrm{mg}$; Cl, $13.1 \mathrm{mg} ; \mathrm{Mg}$, $0.5 \mathrm{~g}$; Fe, $44 \mathrm{mg}$; Cu, $8.0 \mathrm{mg}$; Zn, $110 \mathrm{mg}$; Mn, $43 \mathrm{mg}$; Se, $0.3 \mathrm{mg}$; $1.0 \mathrm{mg}$; vitamin A, 25,013 IU; vitamin $\mathrm{D}_{3}, 4,002 \mathrm{IU}$; vitamin $\mathrm{E}, 135$ $\mathrm{mg}$; vitamin $\mathrm{K}_{3}, 2.1 \mathrm{mg}$; vitamin $\mathrm{C}$, $0.3 \mathrm{~g}$; vitamin $\mathrm{B}_{1}, 8.2 \mathrm{mg}$; vitamin $\mathrm{B}_{2}, 10.2 \mathrm{mg}$; vitamin $\mathrm{B}_{3}, 34.9 \mathrm{mg}$; vitamin $\mathrm{B}_{5}, 18 \mathrm{mg}$; vitamin $\mathrm{B}_{6}, 10$ $\mathrm{mg}$; vitamin $\mathrm{B}_{12}, 0.1 \mathrm{mg}$; biotin, $0.2 \mathrm{mg}$; folate, $0.7 \mathrm{mg}$; choline $0.4 \mathrm{~g}$.

${ }^{2}$ Values in grams per kilogram of DM unless stated otherwise.

${ }^{3}$ Calculated content

$\sim 43^{\circ} \mathrm{C}$. Calves were fed from buckets at 0630 and 1600 h. The MR refusals were weighed and recorded twice a day (maximum 60 min after feeding). After MR feeding, SF was provided in the buckets. The SF refusals were collected before the next MR feeding, in separate buckets, and weighed and recorded once a week. Calves were allowed ad libitum access to water.

\section{Experimental Procedures}

Intravenous Glucose Tolerance Test. An intravenous glucose tolerance test (IVGTT) was performed on $\mathrm{d} 8,29,50$, and 71 of the trial. Prior to the first 3 IVGTT, all calves were fasted for 15 to $20 \mathrm{~h}$. Before the last test, $\mathrm{SF}$ calves were fasted for a longer time period (20 to $30 \mathrm{~h}$ ) to prevent strong interference of nutrient absorption from rumen fermentation.

At least $1 \mathrm{~h}$ before the IVGTT, the calves were prepared with a central venous catheter (Intraflon 2, 14G $80 \mathrm{~mm}$, Vygon Nederland BV, Valkenswaard, the Netherlands) in a jugular vein for glucose infusion and blood sampling. At $t=0 \mathrm{~min}$, an intravenous glucose bolus of $0.18 \mathrm{~g} / \mathrm{kg}$ of BW (20\% glucose solution, Baxter, Utrecht, the Netherlands) was administered within 2 min. Blood samples were collected at $t=-4,-2,4,8$, $12,18,24,30,36,45$, and 60 min relative to the glucose bolus. Blood samples were transferred immediately into 6-mL lithium-heparin vacutainer tubes (Becton Dickinson, Breda, the Netherlands) and stored on ice. Plasma was collected, after centrifugation, within 45 min after blood sampling and stored at $-20^{\circ} \mathrm{C}$ until analysis of plasma glucose and insulin.

The insulin sensitivity index $\left(\mathrm{IS}_{\mathrm{i}}\right)$ was calculated from the following equation, proposed by Tura et al. (2010):

$$
\mathrm{IS}_{\mathrm{i}}=\alpha \frac{K_{g}}{\Delta \mathrm{AUCins} / \mathrm{T}},
$$

Table 2. Feeding schemes of veal calves fed either a milk replacer (MR) diet (CON), a MR diet with the addition of short-chain fructooligosaccharides (FOS), or progressively weaned to only solid feed (SF)

\begin{tabular}{|c|c|c|c|c|c|c|c|}
\hline $\begin{array}{l}\text { Experimental } \\
\text { week }\end{array}$ & \multicolumn{2}{|c|}{$\mathrm{CON}$} & \multicolumn{3}{|c|}{ FOS } & \multicolumn{2}{|c|}{$\mathrm{SF}$} \\
\hline 1 & 400 & 0 & 400 & 0 & - & 400 & 0 \\
\hline 2 & $450-600$ & 59 & $450-600$ & 59 & 0.78 & $450-575$ & 59 \\
\hline 3 & $600-700$ & 135 & $600-700$ & 135 & 1.05 & $575-625$ & 187 \\
\hline 4 & $725-900$ & 198 & $725-900$ & 198 & 1.21 & $650-800$ & 438 \\
\hline 7 & $1,050-1,150$ & 374 & $1,050-1,150$ & 374 & 1.76 & $800-700$ & 882 \\
\hline 8 & $1,150-1,225$ & 245 & $1,150-1,225$ & 245 & 1.83 & $700-550$ & 983 \\
\hline 9 & $1,250-1,288$ & 438 & $1,250-1,288$ & 438 & 2.03 & $500-250^{4}$ & 1,726 \\
\hline 10 & $1,300-1,400$ & 376 & $1,300-1,400$ & 376 & 2.10 & - & 2,158 \\
\hline
\end{tabular}

${ }^{1}$ Daily portion was equally divided over 2 feedings. The MR was fed at a concentration of $125 \mathrm{~g}$ of MR/L. Values represent amounts at the beginning and end of the week, respectively.

${ }^{2}$ Solid feed consisted of $70.9 \%$ concentrates, $14.5 \%$ wheat straw, and $14.6 \%$ alfalfa (based on DM).

${ }^{3}$ Daily portion was equally divided over 2 feedings and provided with the MR.

${ }^{4}$ Calves were weaned from the MR from d 6 during this week. 
where $\alpha$ is a scaling factor $(\alpha=0.276), K_{q}$ is rate of glucose disappearance (slope of log glucose), $\Delta \mathrm{AUC}_{\text {ins }}$ is the area under the curve (above basal) of insulin, calculated using the trapezoid method (Le Floch et al., 1990), and $\mathrm{T}$ is the time interval between 8 and $60 \mathrm{~min}$ (= $52 \mathrm{~min}$ ) when $K_{g}$ and $\Delta \mathrm{AUC}_{\text {ins }}$ are computed.

\section{Milk Tolerance Test}

A milk tolerance test (MTT) was performed on d 22 and 64 of the trial. Prior to the first MTT, all calves were fasted for 16 to $21 \mathrm{~h}$. Prior to the last MTT, SF calves were fasted for a longer time period (20 to $25 \mathrm{~h}$ ).

All calves received $7.6 \mathrm{~g}$ of $\mathrm{MR}$ per $\mathrm{kg}$ of $\mathrm{BW}(t=$ $0 \mathrm{~min})$. Blood was collected from a jugular vein by venipuncture, at $t=-5,30,60,120,180,240$, and 360 min relative to feeding. Blood samples were transferred immediately into 4-mL lithium heparin vacutainer tubes (Becton Dickinson) for glucose and insulin analyses and stored on ice, and into 4-mL sodium fluoride/ potassium oxalate vacutainer tubes (Becton Dickinson) for nonesterified fatty acid (NEFA) analysis. Plasma was collected, after centrifugation, within 45 min after blood sampling and stored at $-20^{\circ} \mathrm{C}$ until analysis.

For glucose and insulin, the $\Delta \mathrm{C}_{\max }$ (= maximum concentration - fasting concentration), time to maximum concentration, and incremental area under the curve $\left(\mathrm{iAUC}_{0-6 \mathrm{~h}}\right)$ were calculated. For NEFA, the $\Delta \mathrm{C}_{\min }(=$ fasting concentration - minimum concentration) and time to maximum concentration was calculated. The iAUC $_{0-6 \mathrm{~h}}$ was calculated using the trapezoid method (Le Floch et al., 1990).

\section{Laboratory Analyses}

Plasma glucose was measured on a Roche-Hitachi Modular automatic analyzer (Roche Diagnostics, Basel, Switzerland) using an enzymatic colorimetric method. The within- and between-run CV was $\leq 2 \%$. Insulin was analyzed using a bovine ELISA kit (Mercodia, Uppsala, Sweden). The within- and between-run CV was $\leq 5.6$ and $8.2 \%$, respectively. The NEFA was analyzed using a NEFA FS kit (Diasys, Holzheim, Germany). The within- and between-run CV was $\leq 2 \%$.

\section{Statistical Analyses}

The SPSS (version 22, IBM, SPSS Inc., Chicago, IL) statistical software was used for all statistical analyses. Data are presented as means \pm SEM. Insulin sensitivity, glucose disappearance rate $\left(K_{g}\right)$, and insulin response (AUCins) during the IVGTT were analyzed for time, treatment, and time $\times$ treatment effects using the mixed effects model procedure. Time, treatment, and their interaction were used as fixed terms, and time as repeated variable within calf. Based on fit statistics (Akaike and Bayesian information criteria), the heterogeneous first-order autoregressive covariance structure was used for all models. When a significant interaction was found, treatment effects were analyzed for each time point separately.

The fasting and postprandial blood parameters (i.e., $\Delta \mathrm{C}_{\max }$, time to maximum/minimum, and $\left.\mathrm{iAUC}_{0-6 \mathrm{~h}}\right)$ were also analyzed for time, treatment, and time $\times$ treatment effects using the mixed effects model procedure. Time, treatment, and their interaction were used as fixed terms, and time as repeated variable within calf. Based on fit statistics (Akaike and Bayesian information criteria), the heterogeneous first-order autoregressive covariance structure was used for all models. When a significant interaction was found, treatment effects were analyzed for each time point separately. Fasting insulin levels were not statistically evaluated because most values were between the limit of detection and the limit of quantification; hence, only means \pm SEM are provided.

The effect of treatment on the average daily gain, calculated over the complete trial period (i.e., BW at end of the trial - BW at start of the trial divided by the length of the trial in days), was assessed using the GLM univariate procedure.

Normality of the model residuals was assessed by visual inspection. Nonnormal distributed data were (log) transformed to obtain normality. $P$-values $<0.05$ were considered significant. When significant, the Bonferroni method was used to correct for multiple comparisons.

\section{RESULTS}

\section{Feed Intake and Growth Performance}

Refusals of MR were negligible throughout the trial. The SF refusals, however, were high $(45 \%)$ at the start of the trial but decreased to $6 \%$ at the end of the trial. Average daily BW gain, measured over the complete trial, was approximately $100 \mathrm{~g}$ lower $(P=0.006)$ in SF calves $(643 \pm 29 \mathrm{~g} / \mathrm{d})$ than in CON and FOS calves $(743 \pm 24 \mathrm{~g} / \mathrm{d}$ and $740 \pm 14 \mathrm{~g} / \mathrm{d}$, respectively).

\section{Insulin Sensitivity, Glucose Disappearance, and Insulin Response}

Whole-body insulin sensitivity decreased $(P<0.01)$ 4 -fold in all groups during the trial (Figure 1). The decrease did not differ between groups (time $\times$ treatment interaction, $P>0.05$ ). The rate of glucose dis- 
appearance $\left(K_{q}\right)$ during the IVGTT decreased $(P<$ 0.01 ) by $22 \%$ during the trial. The decrease did not differ between groups (time $\times$ treatment interaction, $P>0.05$ ). The total insulin response (AUCins) to the intravenous glucose bolus increased $(P<0.01) 2.9$-fold during the trial. However, the increase did not differ between groups (time $\times$ treatment interaction, $P>0.05$ ).

\section{Fasting Levels and Postprandial Responses of Plasma Glucose, Insulin, and NEFA}

Fasting levels and responses of plasma glucose, insulin, and NEFA to the MTT are shown in Figure 2 and Table 3. Compared with the start of the trial, fasting plasma glucose concentrations were higher $(P<0.001$; Table 3) at end of the trial in CON and FOS calves, but lower $(P<0.01)$ in SF calves (time $\times$ treatment, $P<$ 0.001). Fasting plasma insulin levels changed numerically for all treatment groups during the trial (significance could not be tested as most of the observations were between the limit of detection and the limit of quantification). Compared with the start of the trial, fasting plasma NEFA concentrations were higher at end of the trial in SF $(P<0.001)$ and FOS calves $(P$ $<0.05$ ), but did not change over time in CON calves (time $\times$ treatment interaction, $P<0.001$ ). At end of the trial, fasting plasma NEFA concentrations were markedly higher $(P<0.001)$ in SF calves than in CON and FOS calves.

For $\mathrm{SF}$ calves, the time to maximum $\left(\mathbf{T}_{\max }\right)$ for plasma glucose after the MTT at the end of the trial was delayed by more than $100 \min (P<0.001)$ when compared with the start of the trial, whereas $\mathrm{T}_{\max }$ for plasma glucose was unaffected in CON and FOS calves (time $\times$ treatment interaction, $P<0.001$ ). Consequently, at end of the trial, $\mathrm{T}_{\max }$ for plasma glucose was markedly larger $(P<0.001)$ for SF calves than for $\mathrm{CON}$ and FOS calves. For SF calves, $\mathrm{T}_{\max }$ for plasma insulin was delayed by more than $60 \mathrm{~min}(P<0.01)$ at the end of the trial when compared with the start of the trial, whereas this was unaffected in CON and FOS calves. The time to minimum $\left(\mathbf{T}_{\min }\right)$ for plasma NEFA was delayed by almost $60 \min (P<0.01)$ when comparing measurements at the end and start of the trial for SF calves, whereas this was unaffected in $\mathrm{CON}$ and FOS calves (time $\times$ treatment interaction, $P<$ $0.05)$. Consequently, at end of the trial, $\mathrm{T}_{\min }$ for plasma NEFA was markedly larger $(P<0.001)$ for SF calves than for CON and FOS calves.

For SF calves, $\Delta \mathrm{C}_{\max }$ for glucose after the MTT was larger $(P<0.01)$ at end than at the start of the trial, whereas $\Delta \mathrm{C}_{\max }$ for the CON and FOS calves remained unaffected (time $\times$ treatment interaction, $P<0.001$ ).
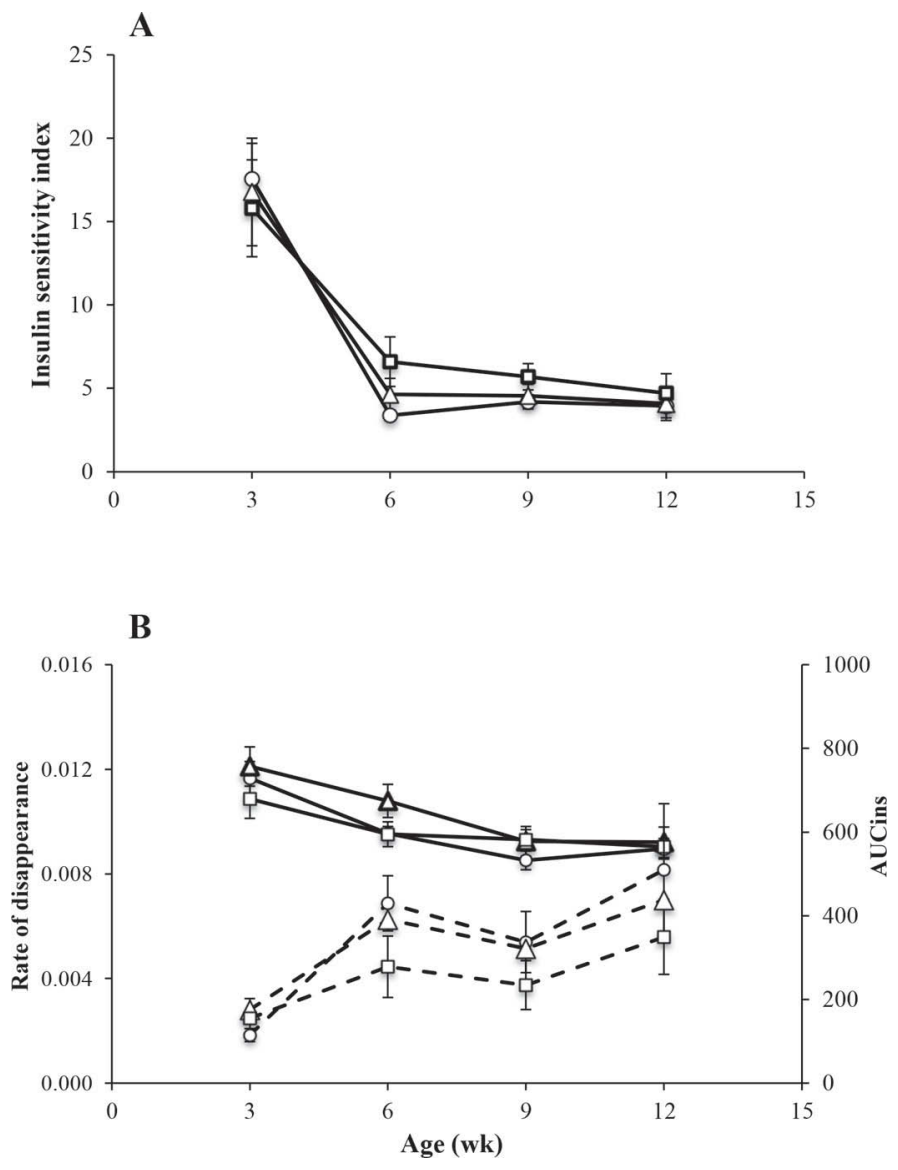

Figure 1. Insulin sensitivity (A), rate of glucose disappearance $\left(K_{g}\right.$; solid lines, B), and insulin response (AUCins; dashed lines, B) to an intravenous glucose tolerance test (IVGTT) in veal calves fed a milk replacer $(\mathrm{MR}) \operatorname{diet}(\mathrm{O} ; \mathrm{n}=10)$, a MR diet with the addition of shortchain fructo-oligosaccharides $(\Delta ; \mathrm{n}=10)$, or progressively weaned to only solid feed $(\square ; \mathrm{n}=10)$. Error bars represent SEM. Significant $(P$ $<0.05)$ time effects were found for all 3 parameters, but no time $\times$ treatment interaction.

Consequently, at end of the trial, $\Delta \mathrm{C}_{\max }$ for glucose was larger $(P<0.01)$ for SF calves than for CON and FOS calves. For all treatment groups, $\Delta \mathrm{C}_{\max }$ for insulin after the MTT was larger $(P<0.05)$ at the end of the trial than at the start of the trial. For SF and FOS calves, $\Delta \mathrm{C}_{\min }$ for NEFA was larger $(P<0.001$ and $P<0.05$, respectively) at the end of the trial, whereas responses of plasma NEFA to the MTT were not affected in CON calves (time $\times$ treatment interaction, $P<0.001$ ). At end of the trial, $\Delta \mathrm{C}_{\min }$ for NEFA was markedly larger $(P<0.001)$ for SF calves than for CON and FOS calves.

The AUC $_{0-6 \mathrm{~h}}$ glucose after the MTT was larger $(P<$ 0.001) at the end than at the start of the trial for $\mathrm{SF}$ calves, but not for CON and FOS calves (time $\times$ treatment interaction, $P<0.001)$. Consequently, at the end of the trial, $\mathrm{AUC}_{0-6 \mathrm{~h}}$ glucose was markedly larger $(P<$ 0.001) for SF calves than for CON and FOS calves. For 
Start of the trial

(calves 5 wk of age)
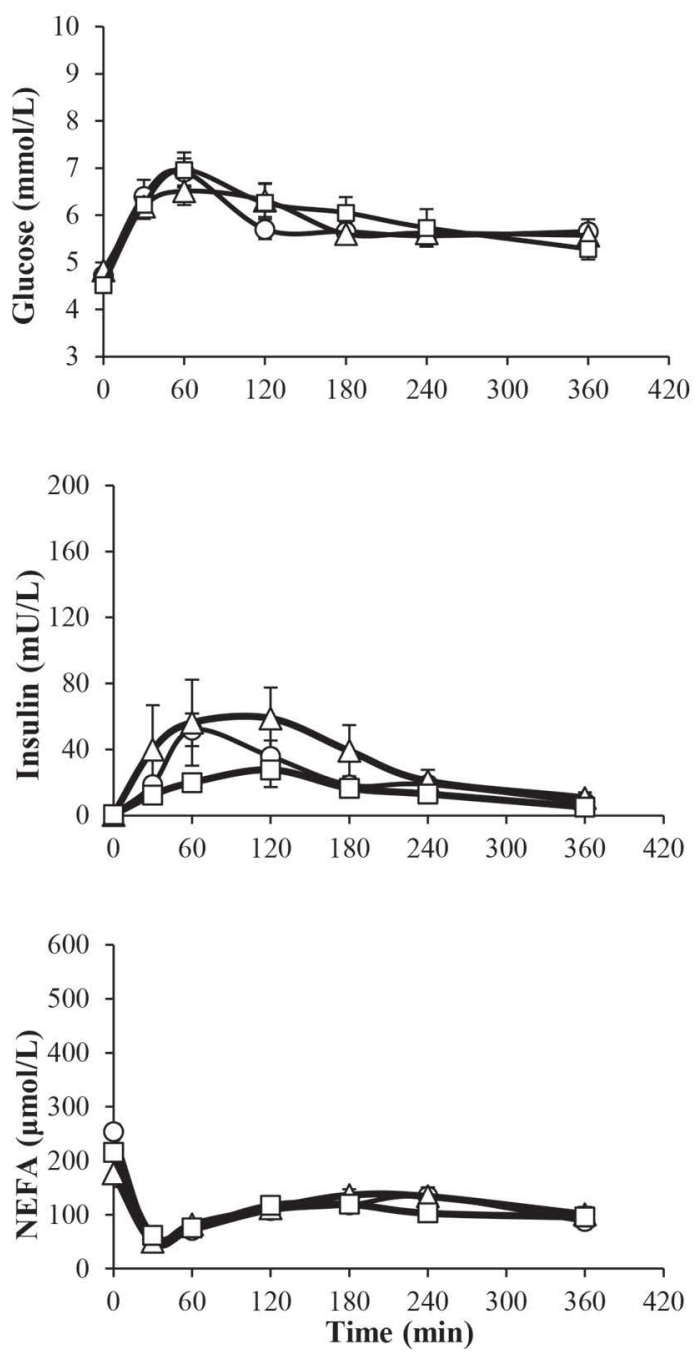

End of the trial

(calves $11 \mathrm{wk}$ of age)
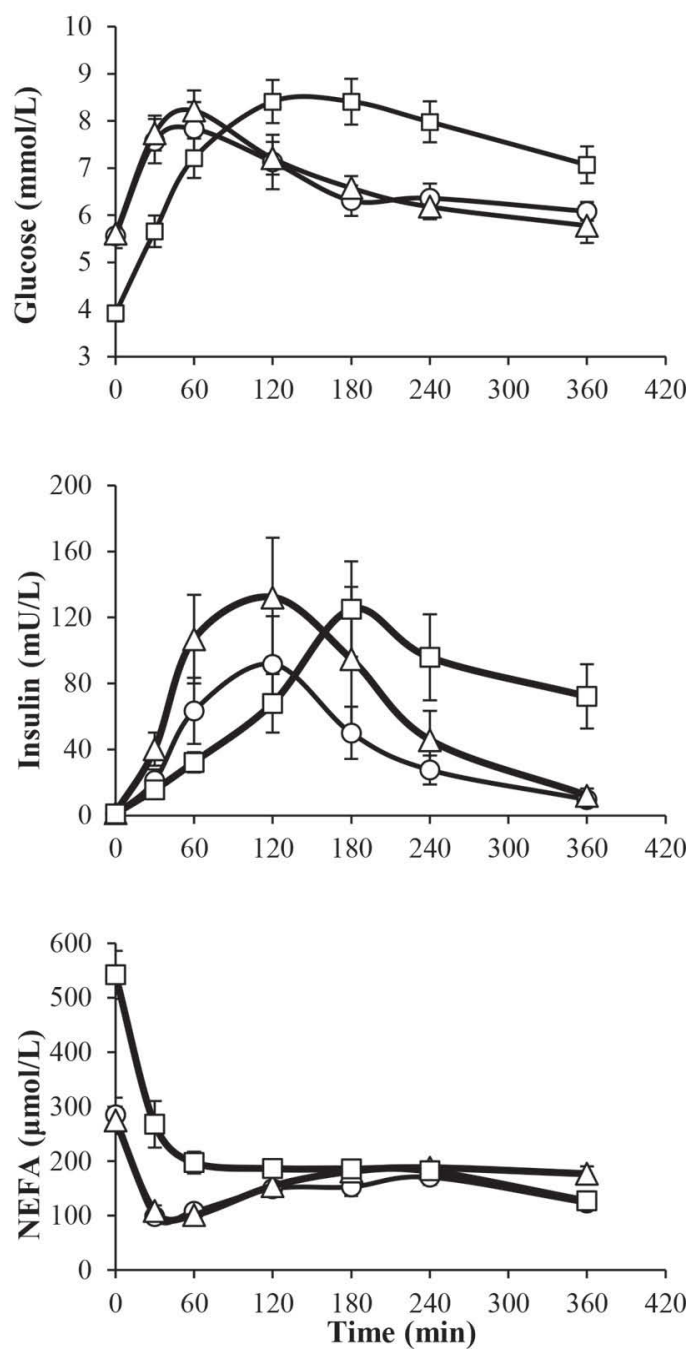

Figure 2. Plasma glucose, insulin, and nonesterified fatty acid (NEFA) responses in calves fed (time $=0)$ a fixed amount of milk replacer (MR), according to their BW (i.e., a milk tolerance test). The tolerance test was performed on d 22 and 64 of the trial. During the trial, calves were fed a MR diet $(\mathrm{O} ; \mathrm{n}=10)$, a MR diet with the addition of short-chain fructo-oligosaccharides $(\Delta ; \mathrm{n}=10)$, or progressively weaned to only solid feed $(\square ; \mathrm{n}=10)$. Error bars represent SEM. Calculated parameters and statistics are given in Table 3.

all treatment groups, $\mathrm{AUC}_{0-6 \mathrm{~h}}$ insulin was increased $(P$ $<0.01)$ at the end compared with the start of the trial.

\section{DISCUSSION}

\section{Growth Performance and Feed Intake}

Average SF refusals were high at start of the trial $(\sim 45 \%)$, but decreased to $\sim 8 \%$ at the end. Although the relative $\mathrm{SF}$ refusals (i.e., expressed as percentage of SF allowance) did not differ between the groups, the absolute amount of SF refusals was higher for SF calves. Therefore, the progressive increase in SF intake in SF calves was limited by their intake capacity during the trial, which resulted in slightly lower average daily $\mathrm{BW}$ gains for SF calves.

\section{Decrease in Insulin Sensitivity}

Insulin sensitivity decreased with age in all treatment groups; the glucose disappearance rate $\left(K_{q}\right)$ decreased with age, whereas the total insulin response (AUCins) increased. Also, the time to peak insulin (response to glucose infusion) did not differ in age or between treatments (data not shown). The age-related decrease in insulin sensitivity found in the current trial is in agree- 
ment with previous studies performed on young calves (Stanley et al., 2002; Bach et al., 2013; Yunta et al., 2015). This is, however, the first study in which this decrease has been assessed and compared in calves that were maintained on MR and calves that were progressively weaned during their first 3 mo of life, indicating that the decrease in sensitivity is independent of feeding strategy. Interestingly, the biggest decrease in insulin sensitivity $(\sim 70 \%$ ), which was $\sim 90 \%$ of the total decrease during the trial period, occurred during the first 3 wk, when calves were 3 to 6 wk of age. During the first 3 wk of the trial, the decrease in insulin sensitivity was not affected by weaning, which may be due to the relatively small differences in feed intake during this period (i.e., when effects may be expected due to the high insulin sensitivity). The age-related decrease in insulin sensitivity has also been observed in young lambs (Gelardi et al., 1999), rats (Torlińska et al., 2000; Yuan et al., 2011), and piglets (Bergeron et al., 2007). Several physiological factors may be involved in the age-related decrease in insulin sensitivity. First, the number of insulin receptors in skeletal muscle, liver, and adipose tissue tend to decrease with age. A study in newborn rats, for example, has shown that the number of high affinity insulin receptors in skeletal muscle substantially decreases between $5 \mathrm{~d}$ to 1 yr of age (Torlińska et al., 2000). Also, a decreased number of skeletal muscle insulin receptors has been found in (insulin resistant) veal calves ( $>4$ mo old) fed a high lactose diet compared with a standard lactose diet (Hugi et al., 1998), suggesting that the number of insulin receptors (and thus insulin sensitivity) is also influenced by nutritional factors. Second, a decrease in the number of insulin- stimulated glucose transporters (GLUT-4) in skeletal muscle and adipose tissue may contribute to the agerelated decrease in insulin sensitivity. For example, an age-related decrease has been reported in epitrochlearis muscles of 1- to 13-mo-old rats (Cartee et al., 1993; Gulve et al., 1993). In neonatal goat and lambs $(<5 \mathrm{wk}$ of age), however, no difference in GLUT-4 was found in adipose tissue and skeletal muscle (Trayhurn et al., 1993; Gelardi et al., 1999). Third, age-related changes in postreceptor insulin signaling proteins such as insulin receptor substrate-1 have been associated with the development of insulin resistance (Carvalho et al., 1996; Nagasaki et al., 2000). These proteins are influenced by nutrients such as glucose, AA, and fatty acids (Blagosklonny, 2013). Nevertheless, further research is required to determine whether a combination of these factors (i.e., insulin receptor, GLUT-4, insulin signaling proteins), or possibly other factors are responsible for the strong age-related decrease in whole body insulin sensitivity in young calves.

In the current study, short-chain FOS did not affect the decrease in insulin sensitivity in young calves. To our knowledge, this is the first study that assessed effects of short-chain FOS on insulin sensitivity in young calves. Kaufhold et al. (2000) studied effects of shortchain FOS supplementation on glucose homeostasis in veal calves at 10 wk of age and found lower glucose and higher insulin peaks after feeding MR, but effects on insulin sensitivity were not assessed. From our previous study, we learned, however, that differences in postprandial glucose homeostasis are not always associated with differences in insulin sensitivity in calves (Pantophlet et al., 2016). In nonruminants, such as dogs

Table 3. Fasting levels and postprandial responses of plasma glucose and insulin, and nonesterified fatty acids (NEFA; means \pm SEM) in veal calves fed a milk replacer $(\mathrm{MR})$ diet $(\mathrm{CON} ; \mathrm{n}=10)$, a $\mathrm{MR}$ diet with the addition of short-chain fructo-oligosaccharides $(\mathrm{FOS} ; \mathrm{n}=10)$, or progressively weaned to only solid feed $(\mathrm{SF} ; \mathrm{n}=10)$

\begin{tabular}{|c|c|c|c|c|c|c|c|c|}
\hline \multirow[b]{3}{*}{ Age (wk) } & \multicolumn{6}{|c|}{ Treatment (Trt) } & & \\
\hline & \multicolumn{2}{|c|}{$\mathrm{CON}$} & \multicolumn{2}{|c|}{ FOS } & \multicolumn{2}{|c|}{$\mathrm{SF}$} & \multicolumn{2}{|c|}{$P$-value } \\
\hline & 5 & 11 & 5 & 11 & 5 & 11 & Time & Time $\times$ Trt \\
\hline \multicolumn{9}{|l|}{ Glucose } \\
\hline Fasting $(\mathrm{mmol} / \mathrm{L})$ & $4.7 \pm 0.2$ & $5.8 \pm 0.3^{\mathrm{a}}$ & $4.8 \pm 0.1$ & $5.6 \pm 0.1^{\mathrm{a}}$ & $4.5 \pm 0.2$ & $3.9 \pm 0.2^{\mathrm{b}}$ & 0.002 & $<0.001$ \\
\hline $\mathrm{T}_{\operatorname{Max}}(\min )$ & $66 \pm 10$ & $51 \pm 6^{\mathrm{a}}$ & $66 \pm 10$ & $63 \pm 7^{\mathrm{a}}$ & $60 \pm 8$ & $162 \pm 16^{\mathrm{b}}$ & $<0.001$ & $<0.001$ \\
\hline \multicolumn{9}{|l|}{ Insulin } \\
\hline Fasting $(\mathrm{mU} / \mathrm{L})$ & $0.9 \pm 0.1$ & $1.6 \pm 0.2$ & $0.8 \pm 0.1$ & $1.6 \pm 0.3$ & $0.9 \pm 0.2$ & $1.3 \pm 0.2$ & - & - \\
\hline $\mathrm{T}_{\text {Max }}(\min )$ & $78 \pm 9$ & $99 \pm 14$ & $102 \pm 19$ & $107 \pm 8$ & $87 \pm 11$ & $150 \pm 18$ & 0.009 & 0.062 \\
\hline$\Delta \mathrm{C}_{\text {Max }}(\mathrm{mU} / \mathrm{L})$ & $60 \pm 11$ & $132 \pm 29$ & $76 \pm 27$ & $182 \pm 39$ & $32 \pm 9$ & $145 \pm 30$ & $<0.001$ & 0.410 \\
\hline iAUC $_{0-6 \mathrm{~h}} \times 10^{3}$ & $8.0 \pm 1.1$ & $19 \pm 3.2$ & $11 \pm 3$ & $23 \pm 5$ & $5.1 \pm 1.3$ & $26 \pm 6$ & $<0.001$ & 0.112 \\
\hline \multicolumn{9}{|l|}{ NEFA } \\
\hline Fasting $(\mu \mathrm{mol} / \mathrm{L})$ & $253 \pm 14$ & $285 \pm 32^{\mathrm{a}}$ & $176 \pm 25$ & $275 \pm 22^{\mathrm{a}}$ & $215 \pm 37$ & $542 \pm 44^{\mathrm{b}}$ & $<0.001$ & $<0.001$ \\
\hline
\end{tabular}

$\overline{\mathrm{a}, \mathrm{b}}$ Different superscripts indicate differences between groups at $11 \mathrm{wk}$ of age $(P<0.05)$. 
and horses, short-chain FOS supplementation improved insulin sensitivity (Respondek et al., 2008, 2011). The absence of an effect of short-chain FOS on insulin sensitivity in young calves is not yet understood, but might be related to differences in the dosage administered (in our study calves received a relatively low dosage compared with, for example, horses), the form or period of administration, digestive or metabolic differences between ruminants and nonruminants, or a combination of these. Explaining interspecies differences in the efficacy of short-chain FOS on insulin sensitivity, therefore, requires additional studies.

\section{Postprandial Responses of Plasma Glucose, Insulin, and NEFA}

For CON and FOS calves, fasting glucose levels increased with age. The increase is in agreement with Hugi et al. (1997), but not with Hostettler-Allen et al. (1994), who found no increase in fasting plasma glucose levels in calves from 5 to 13 wk of age. Fasting insulin increased numerically with age in all treatment groups, which corresponds with an age-related increase in fasting insulin in heavy ( $>4$ mo old) veal calves (Pantophlet et al., 2016). In contrast to CON calves, fasting plasma glucose decreased and NEFA levels increased substantially for the SF calves with age, indicating increased (energetic need for) fat metabolism in these calves. This can likely be explained by a relatively lower ME intake in calves after weaning, as the progressive increase in SF intake was limited by their intake capacity. Similarly, an increase in fat metabolism (and thus NEFA levels) to meet energy requirements after weaning was also seen in early-weaned lambs (Fennessya et al., 1972).

The total plasma insulin response $\left(\mathrm{AUC}_{0-6 \mathrm{~h}}\right.$ insulin) after the MTT increased with age for CON and FOS calves, whereas the total plasma glucose response $\left(\mathrm{AUC}_{0-6 \mathrm{~h}}\right.$ glucose $)$ did not change. This corresponds with the age-related reduction in insulin sensitivity, as more insulin is needed to allow glucose disappearance from the systemic circulation. The $\mathrm{AUC}_{0-6 \mathrm{~h}}$ insulin is however much smaller than in heavy veal calves (Pantophlet et al., 2016). Interestingly, SF calves demonstrated hyperglycemia and hyperinsulinemia (i.e., high and broad glucose and insulin peaks not returning to basal levels) during the second MTT (i.e., postweaning). The reason for this is unclear but might be attributed to several pre- and postabsorptive factors, as these calves might have adapted their digestion and metabolism due to adaptation to SF instead of MR. One factor that could contribute to the delayed glucose peaks is a difference in abomasal emptying rate between milk-fed and weaned calves. Abomasal emptying was shown to occur very rapidly after feeding in milk-fed calves (Labussière et al., 2014), but in weaned calves the emptying rate may be reduced due to an increased consistency of the digesta as affected by greater SF intake. As a consequence, digestion and absorption of carbohydrates from MR may have been delayed. Another explanation could be a decreased activity of lactase in the brush-border of the small intestine, which would shift glucose absorption to a more distal region of the small intestine. Previous studies have shown that lactase activity in milk-fed calves is highest in the proximal small intestine (Le Huerou et al., 1992; Gilbert et al., 2015). Although weaning negatively affects small intestinal lactase activity in calves (Le Huerou et al., 1992), this has not yet been associated with a different site of digestion. In addition to the sustained glucose appearance in SF calves after the MTT, glucose clearance was likely also reduced in these calves (i.e., the high glucose peaks not returning to basal levels within $6 \mathrm{~h}$ after feeding). As insulin sensitivity did not differ between treatments, other underlying mechanisms may operate. First, first pass uptake of glucose by splanchnic tissues (mainly liver and small intestine) and portal-drained viscera (PDV) may decrease upon adaptation of these tissues to the lack of luminal lactose supply after weaning. In steers, for example, infusion of starch into the abomasum increases glucose utilization by the PDV when compared with ruminal infusion (Harmon et al., 2001). Therefore, splanchnic tissues of milk-fed calves may use more glucose in the first pass. Consequently, the postprandial MTT glucose response may have been higher in weaned calves as a combined result of reduced firstpass utilization and a reduced clearance rate of glucose. Second, the relative contribution of glucose transport by insulin-independent transporters (GLUT-1) may be relatively more important in milk-fed than in weaned calves. The age-related development of GLUT-1 and GLUT-4 in milk-fed calves is not known, but Abe et al. (2001) reported that the number of insulin-dependent transporters (GLUT-4) in skeletal muscle and adipose tissues of calves decreases after weaning, whereas the number of GLUT-1 transporters is unaffected. Assuming that the insulin-sensitive GLUT-4 also decreases with age in MR-fed calves (due to the age-related decrease in insulin sensitivity observed in both MR an weaned calves), it might be that, in contrast to weaned calves, glucose transport by insulin-independent transporters increases in MR calves to help facilitate glucose uptake, due to the prolonged high intakes of dietary lactose (i.e., high glucose load). Third, adaptation of the endocrine pancreas to the feeding strategy (e.g., roughage and concentrates vs. milk) or changes in hepatic 
glucose production (e.g., increased gluconeogenesis in ruminants) may also have contributed to the divergent metabolic responses to MR feeding in weaned calves.

\section{CONCLUSIONS}

Whole-body insulin sensitivity decreases by $75 \%$ in calves during the first 3 mo of life, with the most pronounced decrease occurring within the first $6 \mathrm{wk}$. This decrease in insulin sensitivity is not affected by weaning or by supplementation of short-chain FOS. Postprandial insulin increases with age for CON and FOS calves, whereas postprandial glucose remains unaffected, which is consistent with the decrease in insulin sensitivity in calves during early life. After weaning, SF calves show pronounced hyperglycemia and hyperinsulinemia after a milk tolerance test. The underlying mechanisms of this apparent mismatch are not yet known.

\section{ACKNOWLEDGMENTS}

The authors thank Karin Tholen-Cazemier, Gerlof Reckman, and Jeltje Kloosterman for their laboratory assistance (University Medical Centre Groningen, Groningen, the Netherlands), and the animal caretakers at "De Haar," the experimental facilities of VanDrie Group. This project was jointly financed by the European Union, the European Regional Development Fund and the Ministry of Economic Affairs, Agriculture and Innovation, Peaks in the Delta, the Municipality of Groningen, the Provinces of Groningen, Fryslân, and Drenthe as well as the Dutch Carbohydrate Competence Center (CCC2 WP21). Financial support was also provided by Tereos Starch and Sweeteners Europe (Marckolsheim, France), VanDrie Group (Mijdrecht, the Netherlands), and Wageningen University (Wageningen, the Netherlands).

\section{REFERENCES}

Abe, H., Y. Kawakita, K. Hodate, and M. Saito. 2001. Postnatal development of glucose transporter proteins in bovine skeletal muscle and adipose tissue. J. Vet. Med. Sci. 63:1071-1075.

Bach, A., L. Domingo, C. Montoro, and M. Terre. 2013. Short communication: Insulin responsiveness is affected by the level of milk replacer offered to young calves. J. Dairy Sci. 96:4634-4637.

Bergeron, K., P. Julien, T. A. Davis, A. Myre, and M. C. Thivierge. 2007. Long-chain n-3 fatty acids enhance neonatal insulin-regulated protein metabolism in piglets by differentially altering muscle lipid composition. J. Lipid Res. 48:2396-2410.

Blagosklonny, M. V. 2013. TOR-centric view on insulin resistance and diabetic complications: Perspective for endocrinologists and gerontologists. Cell Death Dis. 4:e964.

Cartee, G. D., C. Briggs-Tung, and E. W. Kietzke. 1993. Persistent effects of exercise on skeletal muscle glucose transport across the life-span of rats. J. Appl. Physiol. 75:972-978.
Carvalho, C. R., S. L. Brenelli, A. C. Silva, A. L. Nunes, L. A. Velloso, and M. J. Saad. 1996. Effect of aging on insulin receptor, insulin receptor substrate-1, and phosphatidylinositol 3-kinase in liver and muscle of rats. Endocrinology 137:151-159.

Caumo, A., R. N. Bergman, and C. Cobelli. 2000. Insulin sensitivity from meal tolerance tests in normal subjects: A minimal model index. J. Clin. Endocrinol. Metab. 85:4396-4402.

Fennessya, P. F., M. R. Woodlocka, and K. T. Jaguscha. 1972. The effect of early weaning on the concentrations of non-esterified fatty acids and glucose in the plasma of lambs. N. Z. J. Agric. Res. 15:802-807.

Gelardi, N. L., R. E. Rapoza, J. F. Renzulli, and R. M. Cowett. 1999. Insulin resistance and glucose transporter expression during the euglycemic hyperinsulinemic clamp in the lamb. Am. J. Physiol. 277:E1142-E1149.

Gerrits, W. J. J., J. J. G. C. van den Borne, and J. W. Blum. 2008 Low-dietary protein intake induces problems with glucose homeostasis and results in hepatic steatosis in heavy milk-fed calves. Domest. Anim. Endocrinol. 35:121-129.

Gilbert, M. S., A. J. Pantophlet, H. Berends, A. M. Pluschke, J. J. G. C. van den Borne, W. H. Hendriks, H. A. Schols, and W. J. J. Gerrits. 2015. Fermentation in the small intestine contributes substantially to intestinal starch disappearance in calves. J. Nutr. $145: 1147-1155$.

Gulve, E. A., E. J. Henriksen, K. J. Rodnick, J. H. Youn, and J. O. Holloszy. 1993. Glucose transporters and glucose transport in skeletal muscles of 1- to 25-mo-old rats. Am. J. Physiol. 264:E319E327.

Harmon, D. L., C. J. Richards, K. C. Swanson, J. A. Howell, J. C Mathews, A. D. True, G. B. Huntington, S. A. Gahr, and R. W. Russell. 2001. Influence of ruminal or postruminal starch on visceral glucose metabolism in steers. Pages 273-276 in Energy Metabolism in Animals. EAAP Publication No. 103. A. Chwalibog and K. Jakobsen, ed. Wageningen Pers, Wageningen, the Netherlands.

Hostettler-Allen, R. L., L. Tappy, and J. W. Blum. 1994. Insulin resistance, hyperglycemia, and glucosuria in intensively milk-fed calves. J. Anim. Sci. 72:160-173.

Hotamisligil, G. S. 2006. Inflammation and metabolic disorders. Nature 444:860-867.

Hugi, D., R. M. Bruckmaier, and J. W. Blum. 1997. Insulin resistance, hyperglycemia, glucosuria, and galactosuria in intensively milk-fed calves: Dependency on age and effects of high lactose intake. J. Anim. Sci. 75:469-482.

Hugi, D., L. Tappy, H. Sauerwein, R. M. Bruckmaier, and J. W. Blum. 1998. Insulin-dependent glucose utilization in intensively milk-fed veal calves is modulated by supplemental lactose in an age-dependent manner. J. Nutr. 128:1023-1030.

Kaufhold, J., H. M. Hammon, and J. W. Blum. 2000. Fructo-oligosaccharide supplementation: effects on metabolic, endocrine and hematological traits in veal calves. J. Vet. Med. A Physiol. Pathol. Clin. Med. 47:17-29.

Labussière, E., H. Berends, M. S. Gilbert, J. J. G. C. van den Borne, and W. J. J. Gerrits. 2014. Estimation of milk leakage into the rumen of milk-fed calves through an indirect and repeatable method. Animal 8:1643-1652.

Le Floch, J. P., P. Escuyer, E. Baudin, D. Baudon, and L. Perlemuter. 1990. Blood glucose area under the curve. methodological aspects. Diabetes Care 13:172-175.

Le Huerou, I., P. Guilloteau, C. Wicker, A. Mouats, J. A. Chayvialle, C. Bernard, J. Burton, R. Toullec, and A. Puigserver. 1992. Activity distribution of seven digestive enzymes along small intestine in calves during development and weaning. Dig. Dis. Sci. 37:40-46.

Nagasaki, M., N. Nakai, Y. Oshida, Z. Li, M. Xu, M. Obayashi, T. Murakami, A. Yoshimura, N. Fujitsuka, Y. Shimomura, and Y. Sato. 2000. Exercise training prevents maturation-induced decreases in insulin receptor substrate-1 and phosphatidylinositol 3-kinase in rat skeletal muscle. Metabolism 49:954-959.

Pantophlet, A. J., M. S. Gilbert, J. J. G. C. van den Borne, W. J. J. Gerrits, H. Roelofsen, M. G. Priebe, and R. J. Vonk. 2016. Lactose in milk replacer can partly be replaced by glucose, fructose or 
glycerol without affecting insulin sensitivity in veal calves. J. Dairy Sci. 99:3072-3080.

Respondek, F., K. Myers, T. L. Smith, A. Wagner, and R. J. Geor. 2011. Dietary supplementation with short-chain fructo-oligosaccharides improves insulin sensitivity in obese horses. J. Anim. Sci. 89:77-83.

Respondek, F., K. S. Swanson, K. R. Belsito, B. M. Vester, A. Wagner, L. Istasse, and M. Diez. 2008. Short-chain fructooligosaccharides influence insulin sensitivity and gene expression of fat tissue in obese dogs. J. Nutr. 138:1712-1718.

Shoelson, S. E., S. Lee, and A. B. Goldfire. 2006. Inflammation and insulin resistance. J. Clin. Invest. 116:1793-1801.

Stanley, C. C., C. C. Williams, B. F. Jenny, J. M. Fernandez, H. G. Bateman, W. A. Nipper, J. C. Lovejoy, D. T. Gantt, and G. E. Goodier. 2002. Effects of feeding milk replacer once versus twice daily on glucose metabolism in Holstein and Jersey calves. J. Dairy Sci. 85:2335-2343.

Stefanovski, D., J. M. Richey, O. Woolcott, M. Lottati, D. Zheng, L. N. Harrison, V. Ionut, S. P. Kim, I. Hsu, and R. N. Bergman. 2011. Consistency of the disposition Index in the face of diet induced insulin resistance: Potential role of FFA. PLoS ONE 6:e18134.
Torlińska, T., P. Maćkowiak, L. Nogowski, T. Hryniewiecki, H. Witmanowski, M. Perz, E. Madry, and K. W. Nowak. 2000. Age dependent changes of insulin receptors in rat tissues. J. Physiol. Pharmacol. 51:871-881.

Trayhurn, P., M. E. Thomas, and J. S. Keith. 1993. Postnatal development of uncoupling protein, uncoupling protein mRNA, and GLUT4 in adipose tissues of goats. Am. J. Physiol. 265:R676R682.

Tura, A., S. Sbrignadello, E. Succurro, L. Groop, G. Sesti, and G. Pacini. 2010. An empirical index of insulin sensitivity from short IVGTT: Validation against the minimal model and glucose clamp indices in patients with different clinical characteristics. Diabetologia 53:144-152.

Yuan, Q., L. Chen, C. Liu, L. Xu, X. Mao, and C. Liu. 2011. Postnatal pancreatic islet $\beta$ cell function and insulin sensitivity at different stages of lifetime in rats born with intrauterine growth retardation. PLoS ONE 6:e25167.

Yunta, C., M. Terré, and A. Bach. 2015. Short- and medium-term changes in performance and metabolism of dairy calves offered different amounts of milk replacers. Livest. Sci. 181:249-255. 